\title{
ChemComm
}

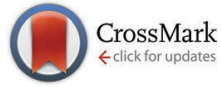

Cite this: Chem. Commun., 2016, 52,8549

Received 11th May 2016

Accepted 9th June 2016

DOI: $10.1039 / c 6 c c 03966 a$

www.rsc.org/chemcomm

\section{A modular approach towards functional supramolecular aggregates - subtle structural differences inducing liquid crystallinity $\dagger$}

\author{
Michael Pfletscher, ${ }^{a}$ Christoph Wölper, ${ }^{b}$ Jochen S. Gutmann, ${ }^{C}$ Markus Mezger ${ }^{d}$ and \\ Michael Giese*a
}

\begin{abstract}
Herein we report an efficient modular approach to supramolecular functional materials. Hierarchical self-assembly of azopyridine derivatives and hydrogen-bond donors yielded discotic assemblies. Subtle differences in the core units introduced mesomorphic behaviour and fast photo-response of the liquid crystals based on phloroglucinol. The presented results prove the benefits of a modular methodology towards highly responsive materials with tailor-made properties.
\end{abstract}

Within the past two decades supramolecular chemistry has developed into a powerful tool to create novel functional materials with fascinating properties. ${ }^{1}$ The employment of non-covalent forces provides many advantages compared to conventional methods and facilitates fabrication, processing and recycling. ${ }^{2}$ Simple mixing of pre-tailored building blocks at room temperature yields highly functional aggregates via self-assembly and allows dynamic response on external stimuli or damages (self-healing/-repair). ${ }^{1 a, 3}$

Supramolecular liquid crystals are functional assemblies showing structural complexity as well as molecular order. ${ }^{4}$ The use of hydrogen-bonds to design novel liquid crystals is appealing and pioneering works of Kato, Fréchet ${ }^{5}$ and Lehn ${ }^{6}$ already yielded supramolecular assemblies with mesomorphic properties. ${ }^{7}$ However, since the self-assembly process depends on a complex interplay of a variety of non-covalent forces the rational design and prediction of properties remains challenging. ${ }^{1 d, 4 a, 8}$

Azobenzenes are frequently used as photo-responsive switches showing reversible trans/cis isomerization upon photoirradiation. ${ }^{9}$

\footnotetext{
${ }^{a}$ Institut für Organische Chemie, Universität Duisburg-Essen, Universitätsstr. 7, 45141 Essen, Germany. E-mail: michael.giese@uni-due.de; Web: http://www.gieselab.de

${ }^{b}$ Institut für Anorganische Chemie, Universität Duisburg-Essen, Universitätsstr. 7, 45141 Essen, Germany

${ }^{c}$ Institut für Physikalische Chemie und CENIDE, Universität Duisburg-Essen, Universitätsstr. 7, 45141 Essen, Germany

${ }^{d}$ Institut für Physik, Johannes Gutenberg-Universität Mainz und Max-Planck-Institut für Polymerforschung, Ackermannweg 10, 55021 Mainz, Germany

$\dagger$ Electronic supplementary information (ESI) available. CCDC 1455700. For ESI and crystallographic data in CIF or other electronic format see DOI: 10.1039/c6cc03966a
}

Azopyridine (Ap) derivatives are promising candidates to develop responsive supramolecular materials since they combine the photo-active azobenzene group with the hydrogen/halogen bond-acceptor capability of the pyridyl-group. .,10 $^{2}$

As already mentioned above a number of hydrogen-bonded liquid crystals were already described. However, the rational design of novel functional materials based on supramolecular assemblies with predictable properties requires a fundamental understanding of the underlying principles and efficient methods to screen a broad variety of influencing factors. Therefore, we herein introduce a modular approach to tailor-made supramolecular liquid crystals (smLCs) by using the principles of crystal engineering and self-assembly. Our first attempt combines commercially available core units (trimesic acid (TA), cyanuric acid (CA) and phloroglucinol (PG)) and simple non-mesogenic azopyridines led to a series of $C_{3}$-symmetric assemblies with liquid crystalline behaviour as well as fast and reversible response to irradiation with light. The intrinsic flexibility of the chosen methodology allows an efficient screening of a wide variety of molecules as potential building blocks for functional materials and provides the opportunity for systematic studies on the structure-property relationship of liquid crystalline assemblies. These fundamental studies are crucial towards the design of efficient functional materials. ${ }^{4,11}$ Inspired by well-established supramolecular synthons ${ }^{12}$ in crystal engineering and supramolecular chemistry promising candidates were selected to create hydrogen-bonded assemblies with liquid crystalline properties. Our initial attempt combines a series of hydrogen-bond donor core units with seven different hydrogen-bond acceptors based on azopyridine (Ap-3-10, blue, see Scheme 1). Mixing the core units with the azopyridines in a ratio of $1: 3$ leads to discotic assemblies, which were investigated in respect to their thermal properties and mesomorphic behavior. So far just a few other examples are reported employing hydrogen bonds to create mesogenic assemblies. $^{8,13}$ In most of these examples at least one of the building block showed mesomorphic behaviour before complexation and no photo-switchable system was described. However, we herein focussing on the modular design of approach allowing for 

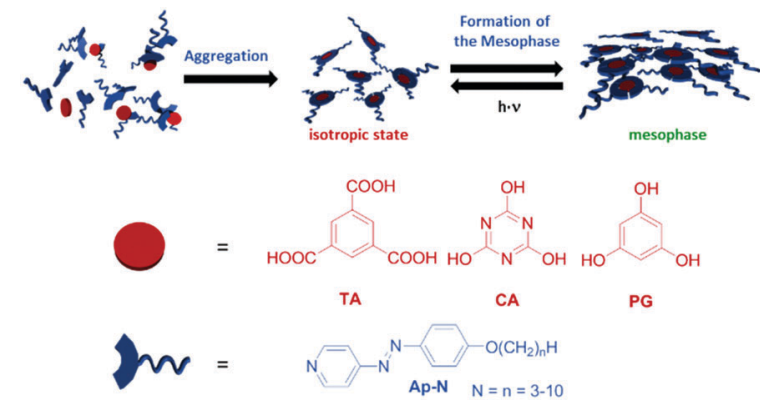

PG

Scheme 1 Modular approach to supramolecular liquid crystals. Initially the core units (TA, CA and PG, red) form hydrogen-bonded assemblies with the azopyridine derivatives (Ap-N, blue). These assemblies organize hierarchically into the nematic mesophase, which can be reversibly switched from meso- to isotropic phase by irradiation with light $(405 \mathrm{~nm})$.

the efficient screening of building blocks and the unique combination their individual properties in a supramolecular assembly.

In order to screen the modular tool box for promising combinations, the commercially available core units were mixed with the azopyridine derivatives in acetone. After removing the solvent the thermal properties of the aggregates were studied under the polarized optical microscope (POM) in a temperature range of 25-150 ${ }^{\circ} \mathrm{C}$. It should be noticed that none of the individual starting materials exhibited mesogenic character. Although all three selected core units exhibit $C_{3}$-symmetry and the general ability to form aggregates with the azopyridine moieties, tremendous differences were found in the mesomorphic behaviour of the assemblies. Intuitively, strong intermolecular interactions are expected between the azopyridine unit and the trimesic cyanuric acid assemblies, while significantly weaker interactions are expected for the hydrogen-bonded phloroglucinol aggregates. However, to our surprise exclusively the phloroglucinol exhibited the formation of stable complexes as proven by POM. The POM images of the 1:3 mixtures of trimesic acid and cyanuric acid with Ap-6, 8 and 10 revealed inhomogeneous melting (Fig. 1A, Fig. S1 and S2, ESI $\dagger$ ). In contrast, the phloroglucinol assemblies melted to a homogeneous isotropic phase (Fig. 1B and Fig. S3, ESI $\dagger$ ).

This observation is attributed to the disaggregation of the hydrogen-bonded trimesic and cyanuric acid aggregates with azopyridine in favour of the stronger hydrogen bonding within the phase separated homo-crystals of the cyanuric and trimesic acid. This is in-line with the significantly higher melting points of trimesic acid $\left(380^{\circ} \mathrm{C}\right)$ and cyanuric acid $\left(320^{\circ} \mathrm{C}\right)$ in respect to phloroglucinol $\left(215^{\circ} \mathrm{C}\right)$. Upon cooling from the isotropic liquid the phloroglucinol series showed a Schlieren texture, characteristic for a nematic mesophase. Therefore, in the following discussion we will focus on the aggregation and characterization of the phloroglucinol system. The hydrogen-bonded aggregates

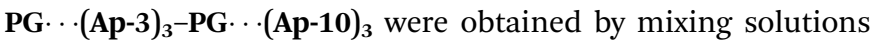
of PG and the corresponding Ap in acetone or by heating mixtures of the pristine starting compounds in a microwave oven. Complexation was confirmed by IR-spectroscopy, single crystal analysis and polarized optical microscopy. Comparison of the IR-spectra (Fig. S4, ESI $\dagger$ ) of the 1:1, 1:2 and 1:3 PG : Ap complexes clearly demonstrates a shift of the broad $\mathrm{OH}$-signal
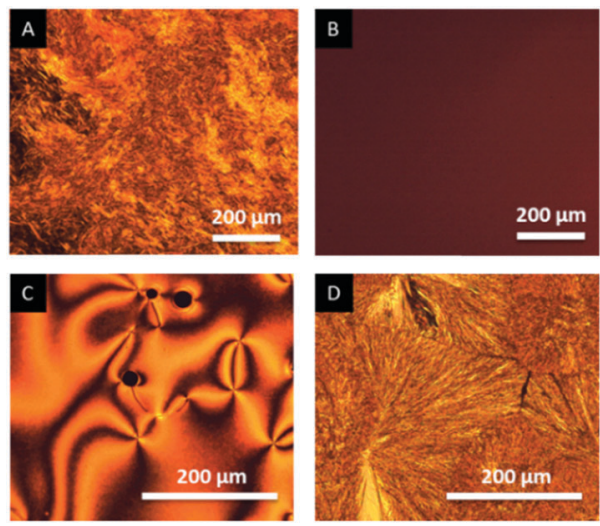

Fig. 1 Representative POM images showing the TA crystallites at $156^{\circ} \mathrm{C}$ (A) as well as the isotropic (B a $110^{\circ} \mathrm{C}$ ), the nematic $\left(\mathrm{C}\right.$ ( $90^{\circ} \mathrm{C}$ ) and the crystalline phase (D a $25^{\circ} \mathrm{C}$ ) of PG ...(Ap-8) $)_{3}$ under crossed polarizers.

of the phloroglucinol from $\sim 3200 \mathrm{~cm}^{-1}$ to $\sim 3050 \mathrm{~cm}^{-1}$ and the appearance of a signal at $\sim 2630 \mathrm{~cm}^{-1}$ indicating the formation of the hydrogen-bonded complex. Similar results were found for the whole series of investigated liquid crystals (Fig. S5, ESI $\dagger$ ).

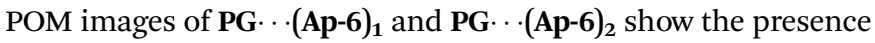
of PG crystallites even at $150{ }^{\circ} \mathrm{C}$ due to incomplete formation of the hydrogen bonded assembly (Fig. S3, ESI $\dagger$ ). Homogeneous melting as well as stable liquid crystalline phases were exclusively found for the 1:3 stoichiometries (Fig. S6, ESI $\dagger$ ).

In order to gain further insight in the molecular structure of the complexes, single crystals of PG . (Ap-4) $)_{3}$ were obtained by slow evaporation of a solutions of PG and Ap-4 in acetone. PG ...(Ap-4) $)_{3}$ crystallizes in the centro-symmetric space group $P 2_{1} / c$ with two hydrogen-bonded assemblies per asymmetric unit cell (see Fig. 2).

The crystal structure clearly shows the hydrogen-bridges between the PG core and the Ap-4 units $\left(\mathrm{N}_{\mathrm{pyr}} \cdot \mathrm{HO}_{\mathrm{PG}}=1.82-1.96 \AA\right)$ and reveals some disorder of the azocompound. The planes of the azopyridine moieties are oriented out of plane in respect to the phloroglucinol $\left(54.9^{\circ}, 63.6^{\circ}\right.$ and $\left.86.1^{\circ}\right)$ unit to form V-shaped assemblies, which are stacked into each other related

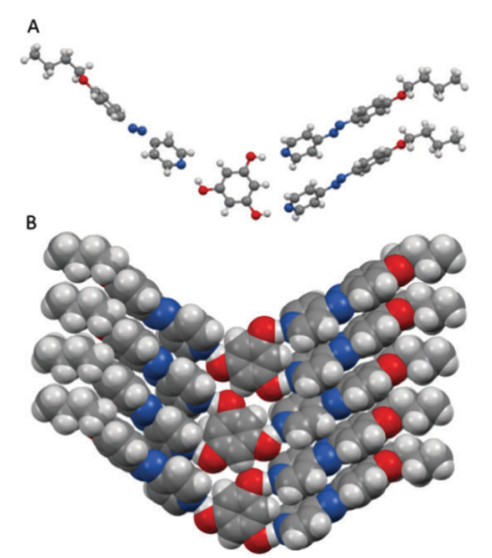

Fig. 2 Molecular structure and intermolecular packing of PG ...(Ap-4) 3 as observed in the solid state (minor component of the disorder omitted for clarity, only one of the two symmetrically independent units displayed). 
by $2_{1}$ symmetry. The phloroglucinol moieties of adjacent hydrogen-bonded aggregates are oriented in the same plane and show non-classical hydrogen-bonding $\left(\mathrm{CH}_{\mathrm{PG}} \cdots \mathrm{OH}_{\mathrm{PG}}=2.37 \AA\right)$. Interestingly, attempts to crystallize the $1: 1$ or $1: 2$ assemblies yielded individual crystals of PG $\cdots(\mathbf{A p}-\mathbf{4})_{3}$ and PG. The crystal structure combined with the obtained IR-spectra and the POM images clarifies the relevance of the hydrogen-bonding and 1:3 stoichiometry of the complexes in order to observe stable mesophases.

The thermal behavior of the mesogens and their individual components were characterized by POM, differential scanning calorimetry (DSC) and X-ray scattering (XRD). As already mentioned above the individual components of the hydrogen-bonded assembly (PG and Ap-3-Ap-10) did not show mesomorphic behavior as proven by POM. The same was found for PG ...(Ap-3) which is not a liquid crystal and melts isotropically at $142{ }^{\circ} \mathrm{C}$. However, the hydrogen-bonded assemblies of PG with Ap-4-Ap-10 clearly show the characteristic textures of a nematic mesophase upon cooling the samples from $\sim 110{ }^{\circ} \mathrm{C}$ to room temperature (Fig. 3 and Fig. S7, ESI $\dagger$ ). In order to quantify the observations made by POM, DSC profiles of the hydrogen-bonded assemblies were collected (Fig. S7 and Table S8, ESI $\dagger$ ). Comparison of the thermal properties indicates a significant stabilization of the mesophase upon elongation of the alkylchain at the peripheral unit. Changes of $\Delta T=5.6{ }^{\circ} \mathrm{C}$ for PG $\cdots(\mathbf{A p}-4)_{3}$ to $\Delta T=26.7{ }^{\circ} \mathrm{C}$ for PG ...(Ap-9) $)_{3}$ were observed. Interestingly, exclusively the PG . (Ap-8) $)_{3}$ and PG . (Ap-9) $)_{3}$ aggregates revealed enantiotropic phase transition showing mesogenic behavior upon cooling and heating. However, the mesophases upon heating are found to be quite narrow $\left(\sim 4{ }^{\circ} \mathrm{C}\right.$, Fig. S7E and F, ESI $\left.\dagger\right)$. In contrast, a related system reported by Jho and coworkers ${ }^{13 j}$ exhibited an enantiotropic mesophase range of more than $40{ }^{\circ} \mathrm{C}$. This difference is most likely attributed to the repulsive forces of the azo-groups and again shows how subtle structural changes significantly influence the properties of supramolecular materials.

XRD measurements on PG - (Ap-6) $)_{3}$ confirmed the formation of nematic mesophases (Fig. 4). In the isotropic melt $\left(100{ }^{\circ} \mathrm{C}\right)$, the diffraction patterns show two diffuse halos at $2 \theta=3.5^{\circ}$ and $20^{\circ}$. This corresponds to real space distances of $25 \AA$ and

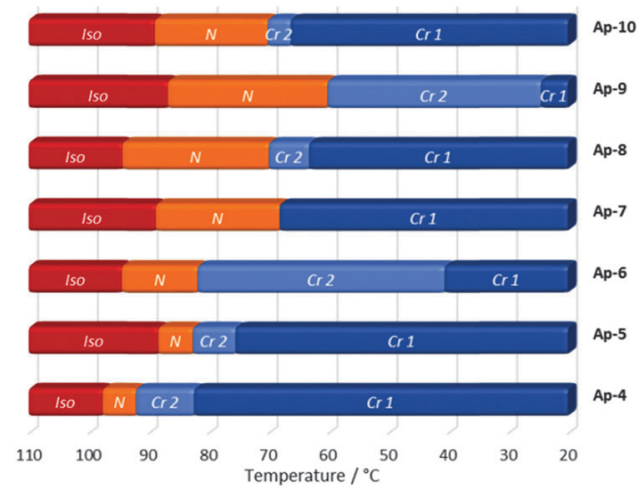

Fig. 3 Monotropic phase transition temperatures upon cooling $\left(10 \mathrm{~K} \mathrm{~min}^{-1}\right.$ ) of the PG ...(Ap-N) $)_{3}$ assemblies as observed by DSC (Iso = isotropic phase, $\mathrm{N}=$ nematic phase, $\mathrm{Cr}=$ crystalline state).

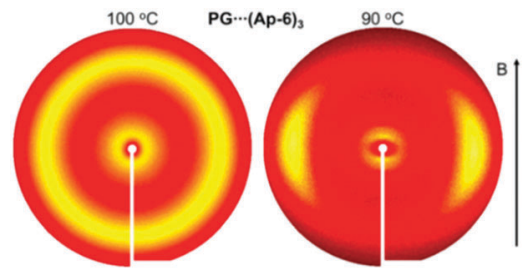

Fig. $4 X$-ray diffraction pattern of PG ...(Ap-6) 3 in the isotropic (left) and nematic phase (right) in a magnetic field.

4.5 Å respectively. Upon cooling to $90{ }^{\circ} \mathrm{C}$ in a vertical magnetic field of approx. $500 \mathrm{G}$ two sets of diffuse peaks at $3.2^{\circ}$ and $20^{\circ}$ are observed. They are oriented perpendicular to each other, confirming the formation of a nematic phase.

The peripheral units of the hydrogen-bonded complexes are based on azopyridine, enabling fully reversible trans/cis isomerization when irradiated with UV-light. ${ }^{9 a, 14}$ The UV-Vis-spectra of thin films of the molten liquid crystals were obtained showing strong absorption in the region of 280 to $410 \mathrm{~nm}$ with an absorption maximum at $365 \mathrm{~nm}$ (Fig. S8, ESI $\dagger$ ).

In order to investigate the photo-responsive properties of the liquid crystals, the samples were irradiated with a laser pointer (405 nm, $5 \mathrm{~mW}$ ) in their mesophases. The effect was in situ followed by POM. For all investigated assemblies the same effect was found. Initially the liquid crystal is present in its trans-state showing the characteristic Schlieren texture of a nematic phase. However, upon irradiation at $405 \mathrm{~nm}$ the birefringent liquid crystal texture disappeared instantaneously (see Fig. 5 and Fig. S9, Video S1, ESI $\dagger$ ) demonstrating a photo-induced phase transition from the meso- to the isotropic phase. The phase transition is attributed to the photo-isomerization of the azopyridine units from their trans to cis form as the bent-shaped cis-isomers tend to destabilized the order of the mesophase. ${ }^{15}$ As soon as the irradiation is stopped the mesophase is recovered within seconds, which is in accordance to previous results found for the thermal relaxation of azopyridines. ${ }^{9 a, 14}$

In order to confirm that the observed photoinduced phase transition is caused by cis/trans isomerization of the azopyridine, the same sample was irradiated with a green $(532 \mathrm{~nm}, 5 \mathrm{~W})$ and a red laser pointer $(650 \mathrm{~nm}, 5 \mathrm{~mW})$. No effect on the mesophases

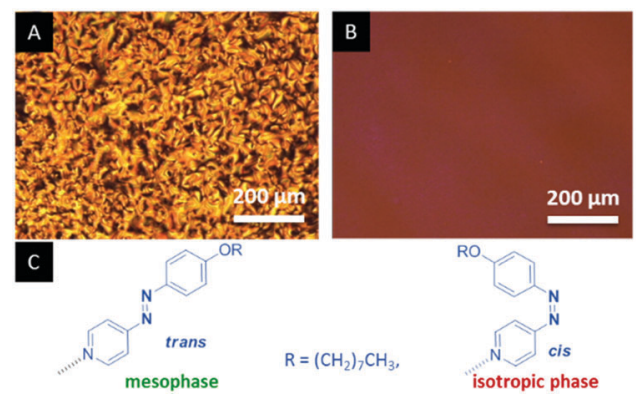

Fig. 5 Photoinduced phase transition of PG...(Ap-8) 3 from the mesophases (A) to the isotropic state (B) upon irradiation at $405 \mathrm{~nm}(5 \mathrm{~mW})$ at $\sim 90{ }^{\circ} \mathrm{C}$ as well as a scheme illustrating the trans/cis isomerization of the azopyridine unit causing the disorder of the LC phase (C). Similar results were found for the PG complexes of Ap-4-10. 
was observed (Fig. S10 and S11, Videos S2 and S3, ESI $\dagger$ ). Therefore, we attribute the previously observed phase transition to the isomerization of the azopyridine moiety and not by local thermal excitation.

In summary, we reported an approach to supramolecular functional assemblies based on azopyridine derivatives. A series of novel hydrogen-bonded liquid crystals were synthesized and characterized exhibiting rapid photo-response, which makes these materials appealing for applications in organic opto-electronics such as sensors or optical gates. ${ }^{16}$ The present study is a proof of principle and demonstrates the utility of a modular design allowing efficient screening of a plethora of supramolecular building blocks towards the design of novel functional materials and fundamental studies on the structure-property relationship of liquid crystalline aggregates. Our current research is now evaluating the scope of this approach in respect to establish columnar phases, which have great potential in respect to electronic and photonic devices. ${ }^{4 d, 17}$

M. G. and M. P. were generously supported by the Professor Werdelmann Stiftung and the Fonds der chemischen Industrie. We thank Professor Christian Mayer and Kirsten Schwark for their experimental assistance (DSC).

\section{References}

1 (a) X. Yan, F. Wang, B. Zheng and F. Huang, Chem. Soc. Rev., 2012, 41, 6042; (b) K. Liu, Y. Kang, Z. Wang and X. Zhang, Adv. Mater., 2013, 25, 5530; (c) R. Dong, Y. Zhou, X. Huang, X. Zhu, Y. Lu and J. Shen, Adv. Mater., 2015, 27, 498; (d) D. González-Rodríguez and A. P. H. J. Schenning, Chem. Mater., 2011, 23, 310.

2 Y. Long, J.-f. Hui, P.-p. Wang, G.-1. Xiang, B. Xu, S. Hu, W.-C. Zhu, X.-Q. Lü, J. Zhuang and X. Wang, Sci. Rep., 2012, 2, 612.

3 (a) Y. Yang and M. W. Urban, Chem. Soc. Rev., 2013, 42, 7446; (b) G. Li, J. Wu, B. Wang, S. Yan, K. Zhang, J. Ding and J. Yin, Biomacromolecules, 2015, 16, 3508; (c) Y.-G. Jia and X. X. Zhu, Chem. Mater., 2015, 27, 387; (d) M. Nakahata, Y. Takashima and A. Harada, Macromol. Rapid Commun., 2016, 37, 86.

4 (a) T. Kato, N. Mizoshita and K. Kishimoto, Angew. Chem., Int. Ed., 2006, 45, 38; (b) T. Kato, T. Yasuda, Y. Kamikawa and M. Yoshio, Chem. Commun., 2009, 729; (c) C. Tschierske, Angew. Chem., Int. Ed., 2013, 52, 8828; (d) T. Wöhrle, I. Wurzbach, J. Kirres, A. Kostidou, N. Kapernaum, J. Litterscheidt, J. C. Haenle, P. Staffeld, A. Baro, F. Giesselmann and S. Laschat, Chem. Rev., 2016, 116, 1139.

5 (a) T. Kato and J. M. J. Fréchet, J. Am. Chem. Soc., 1989, 111, 8533; (b) T. Kato, T. Uryu, F. Kaneuchi, C. Jin and J. M. J. Fréchet, Liq. Cryst., 1993, 14, 1311; (c) T. Kato, T. Kato, J. M. J. Fréchet, T. Uryu, F. Kaneuchi, C. Jin and J. M. J. Fréchet, Liq. Cryst., 2006, 33, 1429.

6 (a) M. Suárez, J.-M. Lehn, S. C. Zimmerman, A. Skoulios and B. Heinrich, J. Am. Chem. Soc., 1998, 120, 9526; (b) M.-J. Brienne, J. Gabard, J.-M. Lehn and I. Stibor, J. Chem. Soc., Chem. Commun., $1989,1868$.

7 (a) C. Domínguez, B. Heinrich, B. Donnio, S. Coco and P. Espinet, Chem. - Eur. J., 2013, 19, 5988; (b) C. Dominguez, B. Donnio, S. Coco and P. Espinet, Dalton Trans., 2013, 42, 15774; (c) A. B. Miguel-Coello, M. Bardají, S. Coco, B. Donnio, B. Heinrich and P. Espinet, Inorg. Chem., 2014, 53, 10893.
8 M. Lehmann, Chem. - Eur. J., 2009, 15, 3638.

9 (a) J. García-Amorós and D. Velasco, Beilstein J. Org. Chem., 2012, 8, 1003; (b) A. Goulet-Hanssens and C. J. Barrett, J. Polym. Sci., Part A: Polym. Chem., 2013, 51, 3058; (c) D. Iqbal and M. Samiullah, Materials, 2013, 6, 116; (d) C. Zong, Y. Zhao, H. Ji, X. Han, J. Xie, J. Wang, Y. Cao, S. Jiang and C. Lu, Angew. Chem., Int. Ed., 2016, 55, 3931; (e) Y. Norikane, Y. Hirai and M. Yoshida, Chem. Commun., 2011, 47, 1770; $(f)$ S. Yagai, T. Nakajima, T. Karatsu, K.-I. Saitow and A. Kitamura, J. Am. Chem. Soc., 2004, 126, 11500; $(g)$ S. Yagai, T. Nakajima, K. Kishikawa, S. Kohmoto, T. Karatsu and A. Kitamura, J. Am. Chem. Soc., 2005, 127, 11134.

10 (a) Y. Chen, H. Yu, L. Zhang, H. Yang and Y. Lu, Chem. Commun., 2014, 50, 9647; (b) O. S. Bushuyev, T. C. Corkery, C. J. Barrett and T. Friscic, Chem. Sci., 2014, 5, 3158.

11 (a) R. J. Bushby and O. R. Lozman, Curr. Opin. Solid State Mater. Sci., 2002, 6, 569; (b) S. Sergeyev, W. Pisula and Y. H. Geerts, Chem. Soc. Rev., 2007, 36, 1902.

12 (a) G. R. Desiraju, Angew. Chem., Int. Ed., 1995, 34, 2311; (b) A. Mukherjee, Cryst. Growth Des., 2015, 15, 3076.

13 (a) A. A. Vieira, H. Gallardo, J. Barbera, P. Romero, J. L. Serrano and T. Sierra, J. Mater. Chem., 2011, 21, 5916; (b) A. A. Vieira, E. Cavero, P. Romero, H. Gallardo, J. L. Serrano and T. Sierra, J. Mater. Chem. C, 2014, 2, 7029; (c) A. Kohlmeier and D. Janietz, Liq. Cryst., 2007, 34, 289; (d) S. J. Lee, M. K. You, S. W. Lee, J. Lee, J. H. Lee and J. Y. Jho, Liq. Cryst., 2011, 38, 1289; (e) J. H. Lee, I. Jang, S. H. Hwang, S. J. Lee, S. H. Yoo and J. Y. Jho, Liq. Cryst., 2012, 39, 973; $(f)$ B. Feringán, P. Romero, J. L. Serrano, R. Giménez and T. Sierra, Chem. - Eur. J., 2015, 21, 8859; $(g)$ S. Yagai, Y. Goto, T. Karatsu, A. Kitamura and Y. Kikkawa, Chem. - Eur. J., 2011, 17, 13657; (h) M.-H. Ryu, J.-W. Choi, H.-J. Kim, N. Park and B.-K. Cho, Angew. Chem., Int. Ed., 2011, 50, 5737; ( $i$ ) H. Blanco, V. Iguarbe, J. Barberá, J. L. Serrano, A. Elduque and R. Giménez, Chem. - Eur. J., 2016, 22, 4924; $(j)$ H. Lee, M.-J. Han, S. H. Hwang, I. Jang, S. J. Lee, S. H. Yoo, J. Y. Jho and S.-Y. Park, Tetrahedron Lett., 2005, 46, 7143; $(k)$ H.-K. Lee, H. Lee, Y. H. Ko, Y. J. Chang, N.-K. Oh, W.-C. Zin and K. Kim, Angew. Chem., Int. Ed., 2001, 40, 2669.

14 J. Garcia-Amoros, S. Nonell and D. Velasco, Chem. Commun., 2011, 47, 4022.

15 (a) H. Yu, H. Liu and T. Kobayashi, ACS Appl. Mater. Interfaces, 2011, 3, 1333; (b) H. Liu, T. Kobayashi and H. Yu, Macromol. Rapid Commun., 2011, 32, 378.

16 (a) H. Yu, J. Mater. Chem. C, 2014, 2, 3047; (b) V. Chigrinov, A. Muravski, H. S. Kwok, H. Takada, H. Akiyama and H. Takatsu, Phys. Rev. E, 2003, 68, 061702; (c) O. Yaroshchuk and Y. Reznikov, J. Mater. Chem., 2012, 22, 286; (d) T. Seki, S. Nagano and M. Hara, Polymer, 2013, 54, 6053; (e) M. Giese, T. Krappitz, R. Y. Dong, C. A. Michal, W. Y. Hamad, B. O. Patrick and M. J. MacLachlan, J. Mater. Chem. C, 2015, 3, 1537.

17 (a) Y. Sagara and T. Kato, Nat. Chem., 2009, 1, 605; (b) S. Yazaki, M. Funahashi, J. Kagimoto, H. Ohno and T. Kato, J. Am. Chem. Soc., 2010, 132, 7702; (c) T. Yasuda, T. Shimizu, F. Liu, G. Ungar and T. Kato, J. Am. Chem. Soc., 2011, 133, 13437; (d) B. Soberats, M. Yoshio, T. Ichikawa, X. Zeng, H. Ohno, G. Ungar and T. Kato, J. Am. Chem. Soc., 2015, 137, 13212; (e) H. N. Tsao, H. J. Räder, W. Pisula, A. Rouhanipour and K. Müllen, Phys. Status Solidi A, 2008, 205, 421; $(f)$ V. Percec, M. Glodde, T. K. Bera, Y. Miura, I. Shiyanovskaya, K. D. Singer, V. S. K. Balagurusamy, P. A. Heiney, I. Schnell, A. Rapp, H. W. Spiess, S. D. Hudson and H. Duan, Nature, 2002, 417, 384; $(g)$ W. Pisula, M. Zorn, J. Y. Chang, K. Müllen and R. Zentel, Macromol. Rapid Commun., 2009, 30, 1179; (h) Y. Hong, J. W. Y. Lam and B. Z. Tang, Chem. Soc. Rev., 2011, 40, 5361; (i) S. Laschat, A. Baro, N. Steinke, F. Giesselmann, C. Hägele, G. Scalia, R. Judele, E. Kapatsina, S. Sauer, A. Schreivogel and M. Tosoni, Angew. Chem., Int. Ed., 2007, 46, 4832. 